\title{
O teatro e nossa América
}

\section{The theater and our America}

\author{
Miguel Rubio Zapata ${ }^{1}$ \\ Tradução: Léo Kildare Louback ${ }^{2}$
}




\section{Introdução}

Aqui se publica o discurso de Miguel Rubio Zapata, diretor do Grupo Cultural Yuyachkani, em agradecimento do Título de Doutor Honoris Causa em Arte pela Universidade de Artes de Havana, Cuba. A cerimônia ocorreu no dia 11 de maio de 2010, na sala Manuel Galich, da Casa das Américas de Havana.

As palavras iniciais foram conferidas pela Dra. Raquel Carrió, que destacou a importância do Grupo Yuychkani no contexto teatral latino-americano. Assistiram à cerimônia o Ministro da Cultura de Cuba, Abel Prieto, Roberto Fernández Retamar, Presidente da Casa das Américas, Rolando González Patricio, reitor da Universidade das Artes, diretores da Casa das Artes e atores do grupo peruano e teatreiros cubanos, entre outras personalidades.

Obrigado mestra, companheira, e amiga Raquel Carrío, por suas generosas palavras. Obrigado à Casa das Américas e ao Instituto Superior deArtes (ISA) por este reconhecimento que divido com meus companheiros e companheiras do Yuyachkani, companheiros de tempo, de vento e de luz, aos quais devo minha aprendizagem. Há quarenta anos sou observador de seu crescimento, de sua autonomia como artistas, atores-autores de sua criação. Em nome de cada um deles, faço meu este reconhecimento.

É justo também, de cima deste palco, render homenagem aos mestres que nos formaram, alguns deles sem o saber, como Luis Valdez e seu teatro campesino, de grande inspiração para nós, Augusto Boal, Vicente Revuelta, Flora Lauten, Santiago García, Enrique Buenaventura, Oswaldo Dragún, Roa Luisa Márquez, Antunes Filho, Eugenio Barba. Todos eles vivem em nós.

ISSN: 1414.5731

\footnotetext{
${ }^{1}$ Miguel Rubio Zapata membro fundador do Grupo Cultural Yuyachkani, em 1971, no Perú, e desde então atua como diretor do grupo. Obras publicadas: Notas sobre teatro, Lima, 2000; El cuerpo ausente, performance política, Lima, 2008; Raíces y semillas, maestros y caminos del teatro en América Latina, Lima, 2011.
}

${ }^{2}$ Léo Kildare Louback, ator e dramaturgo, Louback é formado em letras pela Universidade Federal de Minas Gerais e atua ainda como tradutor de alemão. E-mail: leokildareosso@gmail.com 
Nesta nossa Casa das Américas, entendi e senti que sou latino-americano e parte de uma moderna tradição cênica que surgiu em nossa América em meados do século passado. O que é o teatro latino-americano agora? Ocorreu-me ouvir essa pergunta em muitas oportunidades e às vezes me vi obrigado a tentar respondê-la sem ter muito claro o que dizer. E hoje volto à pergunta, pois se trata de um interesse, uma curiosidade, que por alguma razão persiste.

Tenho a impressão de que às vezes costumamos afrontar essa pergunta com uma verbalização grandiloquente, com certa atitude cansativa que se repete ou com meias respostas ditas como que para sair da situação. Em outras ocasiões, a resposta consiste em ignorar a pergunta, desviar-se dela ou buscar saídas rápidas. Mais além do silêncio como opção ou da fuga ante à pergunta, costumam-se ouvir respostas dadas por vozes que se referem ao tema como algo em vigorosa emergência, como se nada houvesse mudado em cinquenta anos ou, em outro extremo, apresentando o teatro latino-americano como um tema velho e superado, sobre o qual temos pouco ou nada a dizer.

Quando a conversa se orienta até esses extremos, o alento se faz curto e o interesse rapidamente desliza até temas considerados "mais atuais", "menos complicados", ou o discurso é levado até o campo da estética ou da técnica, por certo, separado de seu contexto. E, claro, sabemos que muita água correu embaixo da ponte, o tempo não passou em vão, e ademais não vivemos exatamente em tempos que resistam a afirmações ligeiras ou categóricas frente às situações complexas que vivemos. Para dizer a verdade, me sinto parte dessa incerteza e, de alguma maneira, faço meu o conflito de uma definição que nos acerque a um lugar que reflita o momento.

Esse lugar, esta pátria nova que chamamos de Teatro Latino-americano, dá sinais de insurgência em meados do século passado. Trata-se de um paradigma, um sonho compartilhado por muitos, uma grande esperança e, também, resultado da convicção de saber-nos parte de uma grande revolução teatral que andava ao passo de uma grande revolução social que estava cantada e de cujas possibilidades ou iminência duvidávamos. Como todo fenômeno artístico, nossa prática vinha acompanhada de simplificações, de voluntarismo, de retórica etc. Em meio século de história, os fundamentos disso que chamamos a moderna tradição do teatro latino-americano passaram por muitos estágios, nos quais nossos teatros não deixaram de atuar sobre o contexto e o público, de maneiras muito diversas. Nossa dificuldade em assumir o ativo e o passivo dessa memória não nos deve levar à pretensão de ser "modernos", isso incluindo o custo de nossa história recente, como se fosse possível construir o novo omitindo o vivido.

Havendo percorrido um trecho mais largo desse caminho, temos obrigação de nos dirigir principalmente aos jovens insatisfeitos com o teatro que herdaram, para dizer-lhes que alguns de nós também o estamos, que nos cansamos das frases categóricas que afirmam ou negam de maneira absoluta, para dizerlhes que podemos ser do mundo sem renunciar a nossa aldeia, que Godot tem 
parentes que o esperam nestas terras, que Antígona tem aqui tanto irmãs quanto Mãe Coragem tem filhos e Arturo Ui irmãos. Como não? O tempo não passou em vão e, sobreviventes do teatro latino-americano, soubemos relativizar nossas suposições. Por isso seguimos vivos.

Temos que fazer um grande esforço para não adoecermos de esquecimento, sem que a história nos pese tanto que nos impeça de encontrar um equilíbrio entre o passado e o futuro. Nesse andar, os pesos se moveram entre uma América Latina aparentemente obcecada em mirar sua história e as particularidades que a fazem distinta no mundo, e outra Latino-América que parece haver-se inclinado melhor até posições donde prevalece um modelo econômico que subscreve uma globalização "a qualquer custo", ainda que parte do preço a pagar seja o futuro do ser humano. Nós, teatreiros, que antes nos exibíamos com orgulho como parte desse "paraíso exótico" e "berço de revoluções", agora parece que temos grandes dificuldades em saber quem somos e onde estamos parados.

Sinto-me uma testemunha privilegiada por ter vivido perto de momentos em que não havia nenhuma dúvida sobre o tema e onde se subscrevia com orgulho a vitalidade do teatro latino-americano. Conheci mestres e grupos protagonistas dessa história, fundadores dessa moderna tradição teatral sustentada fundamentalmente em coletivos de criação onde aprendemos a inventar, sabendo que a cultura se gesta em cada momento da vida. Posso reconhecer características muito concretas que nos tornava semelhantes e, ao mesmo tempo, diferentes, como são os diversos caminhos do teatro em nosso continente. Com eles, e graças a eles, conhecemos o impulso da criação coletiva, do teatro de grupo, e logramos novos espaços para a cena.

A irrupção de novos personagens, protagonistas de novas histórias, de novos atores, novos espectadores e novos espaços implicou o desenvolvimento de uma dramaturgia nova e complexa, capaz de conter tanta diversidade. Trata-se de todo um conjunto de sinais que nos situava ante um processo em que nos reconhecíamos em um entrelaçado diverso e carregado de matizes, como o são nossas culturas, e dentro dessa diversidade confluente pudemos ser testemunhas e ao mesmo parte de um movimento em crescimento.

Algumas vezes demos motivos para que nosso teatro se associasse a um postura idílica, ingênua, que associa identidade com uma mirada nostálgica e ancorada no passado, e cuja consequência é uma certa simplicidade que certamente gera rechaço.

Isso conduz a outra postura não menos radical que só encontra diferenças e por nenhum lado semelhanças ou fatores comuns. Entendo que na base dessa postura está o rechaço, que compartilho, a certo olhar que associa teatro latino-americano a uma forma de expressão menor, vernácula e acomodada. Nos festivais europeus, muitos queriam ver Macondo em nossas obras, quando não a sensualidade amazônica ou o exotismo das montanhas. Por outro lado, alguns colegas que não encontram razões suficientes para falar de teatro latino-americano, preferem aludir a este como "o teatro que se faz na América Latina", assim simples e ponto final. Outros, a fim de sustentar uma teatralidade originária, 
preferem refugiar-se nas origens pré-hispânicas, como se fosse possível uma cultura se manter imutável no tempo.

Para encontrar os vínculos que nos permitem falar de um teatro latino-americano, é necessário olhar criticamente, e com a menor quantidade de preconceitos possível, nossa quase esquecida história recente. Assim poderemos ver como o essencial dessa grande força e vitalidade do nosso teatro foi possível pela grande confluência sem precedentes de movimentos gerados por atores, autores, diretores, dramaturgos e artistas, procedentes de todas as disciplinas. O grupo foi a célula mãe em que nos organizamos para gerar essa nova teatralidade que reclamávamos aos gritos e que devia marchar em consonância com os tempos em que se vivia, onde predominava um sentimento coletivo. Isso sucedeu paralelamente a outras instancias criativas que deram sinais de fogosa presença, como o chamado boom da literatura, da dança, o novo cinema latino-americano, a fotografia, o documentário, as artes plásticas etc. Isso, por certo, foi um feito estético e fundamentalmente político que estava no marco de um intenso contexto político e social. Os artistas, de forma explícita ou não, estavam refletindo a esperança mobilizadora de nossos povos empenhados em tomar as rédeas de sua história. $\mathrm{E}$ ali, ao lado deles, e não casualmente, estávamos, teatreiros, "inventando auroras", como dizia uma canção popular nicaraguense da época.

Dou-me conta de que esta é uma história mais ou menos conhecida da gente de minha geração, de modo que posso me referir a ela citando alguns episódios, para que o público que é contemporâneo a mim saiba de que estávamos falando. Ao mesmo tempo, comprovo a dificuldade que me causa transmitir essa memória a jovens estudantes, que parecem ter dessa história só um pálido reflexo. Entre eles, reina um desconhecimento desse período não tão distante e, claro, os jovens tem todo o direito de viver seu presente sem carregar um passado que não lhes corresponde. Sem dúvida, tem-se que dizer que às novas gerações deveria ter alguma curiosidade de saber o que fizeram seus pais. Conhecê-los poderia ser de utilidade para eliminar fantasias, localizar-se melhor em seu presente e seguir trabalhando, sem estorvos e sem zonas obscuras na memória, no bom teatro que merecemos.

Viemos de tempos revoltos, mas creio que agora eles o são mais. Tentar uma olhada até à frente implica, sob meu ponto de vista, reconhecer em nós a possibilidade de imaginar o futuro, de inventá-lo, e não somente aceitar o que recebemos como se fosse dado, parte de uma ordem natural incontestável. Implica, também, saber de onde viemos, saber qual é essa memória que temos guardada sobre aquilo que denominamos Teatro Latino Americano, que agora aparece como um lugar inapreensível e, quando não, desconhecido de nossa história, de nossa biografia artística.

Isso significa, também, uma olhada integral que nos permita não só ver textos e autores, senão também movimentos, deslocamentos. Os espetáculos podem ser marcos desse reconhecimento, mas ao mesmo tempo podemos nos acercar dos processos criativos, não só de seus resultados, mas também das linhas pedagógicas. Assim poderíamos ver como tudo isso operou em nossa história recente. 
Se tomássemos como ponto de partida a metade do século passado, veríamos um movimento em processo, um teatro que se lança a inventar-se, a reconhecer suas particularidades como resultado de uma grande e rica diversidade cultural e, ao mesmo tempo, veríamos outros setores sociais tradicionalmente oprimidos mostrando a cara como público, como fazedor e coparticipante primordial. Não é minha intenção fazer um retrospecto histórico, mas sim retomar a tarefa pendente do resgate e da reconstrução de uma memória onde coincida de maneira integral nossa história em todas suas múltiplas vertentes.

Ao meu ver, os melhores momentos, se é que podemos falar de "melhores momentos", ou melhor, os momentos de grande força e singularidade nesta história, foram aqueles em que nosso teatro foi parte da luta de nossos povos por uma vida melhor. Então, nesses momentos, nos atrevemos a reconhecer-nos em nossa particularidade e a inventar criativamente o teatro que nos fazia falta, sem nos vermos obrigados a marchar no compasso das culturas hegemônicas.

Se fico com algo essencial desse processo vivido desde meados do século passado, é com o exercício do teatro como um espaço de criação, pois nossos velhos mestres nos ensinaram a inventar. Essa foi a lição fundamental. Abrir-nos à invenção é o que nos permitiu mudar e transitar pelos caminhos mais diversos, para saber dizer e saber estar no momento apropriado, para nos aproximarmos das formas genuínas de teatralidade nascidas da necessidade de comunicar. Esse foi o caminho que percorri com meu grupo Yuyachkani e nossa história é um episódio, uma pequena parte da história do teatro latino-americano.

Os impulsos que deram origem ao teatro radical e contestatório de meados do século passado não procediam de nenhum esforço voluntarista nem da operação dialética de ideologia alguma. Suas raízes, as que o explicam e the permitiram ser, se fundem à história e surgem da necessidade de refutar a imposição política e cultural derivada da conquista. O teatro europeu foi imposto, desconhecendo-se as formas da representação que habitavam estas terras, as que, no melhor dos casos, foram assinaladas com categorias ocidentais, sendo muitas delas proscritas com argumentos teológicos convergentes com as necessidades da conquista e da dominação.

Durante a conquista e o colonialismo, à exclusão dos indígenas - cujas condições de seres humanos, inclusive, foram postas em dúvida pela ideologia oficial -, correspondeu a exclusão de práticas artísticas e culturais. Estes últimos processos não se podem considerar concluídos ainda hoje. Na missão colonial, aquele que não se pode erradicar foi incorporado para interiorizar os valores do catolicismo, que usou para isso os elementos de representação presentes na dança, na música e na imagem, que posteriormente foram assimilados nas grandes exibições festivas, iniciando-se assim os níveis de mescla e sincretismo com os quais convivemos hoje e os que sustentam o encontro de elementos pré-hispânicos e cristãos em uma conjunção de ritos de diversas procedências. Sensibilizarmo-nos sobre como funciona esse mecanismo sincrético é fundamental para entender a mistura e a "hibridização" de processos culturais em constante movimento.

No curso da Colônia, muitas formas de representação pré-hispânicas assumiram moldes de acordo com os parâmetros do teatro ocidental, ou seja, os 
"gêneros" oriundos encontrados pela conquista foram definidos com referência em um cânone cultural espanhol, o que acarretou a perda das formas originais, castrando sua essência como evento efêmero, em alguns casos ritual e sagrado. Essa história é conhecida e merece ser recordada, porque atualmente seguemse desconhecendo práticas cênicas que não correspondem à hegemonia cultural. Por isso nos parece justo afirmar uma teatralidade complexa, que tenha a ver com reconhecer-nos em uma identidade inclusiva.

As formas dramáticas de origem pré-hispânica são similares a gêneros asiáticos, como o teatro chinês, japonês e hindu, onde, por exemplo, não existe separação entre ator e dançante, e onde se privilegia a experiência do que surge na cena, mais que o que se narra, o que muitas vezes é um pretexto sobre o qual se entrelaçam códigos que compõe o tecido complexo. Devemos a Antonin Artaud, Jerzy Grotowski, Peter Brook e Eugenio Barba, entre outros, haver repensado e ampliado critérios para ascender a outros níveis de entendimento das práticas cênicas. Eles dirigiram um olhar atento ao sagrado, ao ritual e ao antropológico, investigando culturas originárias da Ásia, África, América Latina e Caribe. Esse olhar nos é devolvido como um espelho em cujo reflexo todavia não nos confrontamos de forma suficiente, com esse caudaloso imaginário cênico que habita entre nós desde a origem da nossa civilização.

O teatro é uma construção cultural que nasce de valores determinados de acordo com a comunidade onde surge, respondendo a relações sociais específicas, como foram as que operaram em diferentes momentos da história. O teatro que chega da Espanha é o teatro do pai, que veio e se impôs ao teatro da mãe, da América pré-hispânica, gerado em contextos ritualísticos, celebrações, jogo, dança, mascaramento. Essas formas seguem vivas e cruzaram o tempo com uma mitologia que as sustenta e desde onde se constroem acontecimentos únicos, que evocam formas ancestrais da representação. As novas gerações não têm modelos e nossas fronteiras cênicas estão saudavelmente movidas. Há zonas cada vez mais indefinidas e nelas novos espectadores. Tudo isso situado em um marco cultural expandido e transuniversal.

Torna-se necessário que a linguagem do nosso ofício não resista a usar novos termos e que possamos ir ao encontro de uma teatralidade complexa, que tenha a ver com reconhecer-nos em todos os matizes de uma identidade inclusiva, onde se encontrem os elementos de uma América pré-hispânica, e nela o híbrido, a arte conceitual, o artista objeto e sujeito de sua obra, a negação da representatividade, a intervenção de espaços públicos, as ambientações, a apropriação de tecnologia etc. Todas essas possibilidades cobram sentido e são pertinentes como objeto de exploração, devido à complexidade de nossas sociedades, onde cidadania, exclusão, corrupção e racismo são objetos de protesto permanente. O bom teatro sempre será aquele que funciona nos códigos de sua comunidade sem renunciar a essa complexa relação entre o real e o artifício.

América Latina e Caribe não significam uma coisa única. É o indígena, o africano, o europeu e o contemporâneo, um lugar aberto a todas as práticas cênicas do século XXI. Nosso teatro recolhe o espírito dos três continentes e se 
alimenta culturalmente dessas três raízes e com elas dialoga em igualdade de condições com os teatros de todo o mundo.

Recebido em 15/06/2014 